TI 2015-049/VIII

Tinbergen Institute Discussion Paper

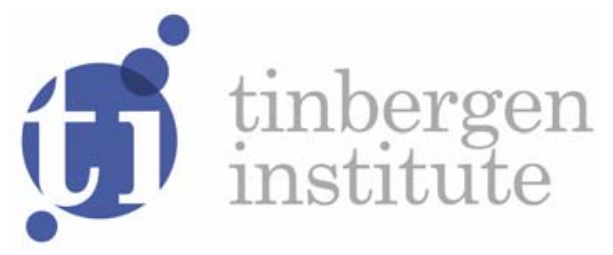

\title{
Single-Till versus Dual-Till Regulation of Airports
}

\author{
Achim I. Czernyl \\ Anmin Zhang'
}

I Faculty of Economics and Business Administration, VU University Amsterdam, and Tinbergen Institute, the Netherlands;

2 University of British Columbia, Canada. 
Tinbergen Institute is the graduate school and research institute in economics of Erasmus University Rotterdam, the University of Amsterdam and VU University Amsterdam.

More TI discussion papers can be downloaded at http://www.tinbergen.nl

Tinbergen Institute has two locations:

Tinbergen Institute Amsterdam

Gustav Mahlerplein 117

1082 MS Amsterdam

The Netherlands

Tel.: +31(0)205251600

Tinbergen Institute Rotterdam

Burg. Oudlaan 50

3062 PA Rotterdam

The Netherlands

Tel.: +31(0)10 4088900

Fax: $+31(0) 104089031$

Duisenberg school of finance is a collaboration of the Dutch financial sector and universities, with the ambition to support innovative research and offer top quality academic education in core areas of finance.

DSF research papers can be downloaded at: http://www.dsf.nl/

Duisenberg school of finance

Gustav Mahlerplein 117

1082 MS Amsterdam

The Netherlands

Tel.: +31(0)20 5258579 


\title{
Single-till versus dual-till regulation of airports ${ }^{1}$
}

\author{
Achim I. Czerny ${ }^{1}$ and Anming Zhang ${ }^{2}$ \\ ${ }^{1}$ Department of Spatial Economics, VU University Amsterdam, and Tinbergen Institute, \\ a.i.czerny@vu.nl \\ ${ }^{2}$ Sauder School of Business, University of British Columbia, anming.zhang@sauder.ubc.ca
}

\begin{abstract}
Most airports operate under public ownership, while some are privatized and economically regulated. Only a few airports are privately owned and experience little or no ex-ante regulation of airport charges. On the other hand, airports nowadays earn as much revenue from transport-related activities as from commercially-oriented business activities. Taken together, these two observations lead to a natural question: How to optimally integrate profits derived from commercial activities into the regulation of airport infrastructure charges? This question is addressed in this chapter. We discuss basic issues that are relevant for the design of regulatory regimes for airports and how these issues can be tackled by using airport profits derived from commercial activities for infrastructure cost recovery. The main insights are summarized at the end of each section and then are further summarized in the conclusions section.
\end{abstract}

\section{Introduction}

The air transport industry is of growing importance as a transportation mode. A crucial element in the value chain is airports, which are heavily regulated in reality. The strongest form of regulation is public ownership, with many airports currently operating under public ownership including airports in the United States. ${ }^{2}$ Yet, starting with the privatization of some UK airports in 1987, a growing number of airports around the world have been privatized, or partially privatized, especially in Europe, Australia, and New Zealand (e.g., Oum et al. 2004, Winston and de Rus 2008, Matsumura and Matsushima 2012, Lin 2013, Noruzoliaee et al. 2014). As the ownership changes from public to private hands, economic regulation may become increasingly necessary, since airports generally exhibit many of the classic properties of local monopolies. In this chapter we discuss how airport price regulation in the form of price-cap regulation can be used to improve the overall performance of the air transport industry and, especially, how airport congestion and concession revenues can contribute to this objective.

We first introduce, in Section 2, a simple airport model with a single aeronautical good to discuss basic issues in airport regulation that are important for the design of the regulatory system. These include the role of airport market power, the "vertical structure" of airport-

\footnotetext{
${ }^{1}$ We thank Ricardo Flores-Fillol and Robin Lindsey for helpful comments. Partial financial support from European Research Council (ERC, AdG Grant \#246969 OPTION) and the Social Science and Humanities Research Council of Canada (SSHRC) is gratefully acknowledged.

${ }^{2}$ However, airports in the United States outsource many of their activities to private companies. This aspect is different from European airports that are used to produce many services in-house (e.g., ground handling).
} 
airline relationship, ${ }^{3}$ delays and congestion at airports, and the growing importance of airport concession revenues. This discussion provides a basic understanding of why price regulation of airports can be beneficial for society as a whole. The discussion further reveals the important insight that welfare-optimal pricing will often lead to airport financial deficits. Accordingly, it is useful to examine how the supply of airport concession services can be used to optimize the pricing and thus the use of airport infrastructure. Specifically, we will discuss the different effects of concession types on the monopoly airport charge for aeronautical services. As revealed in the recent literature, these concession types lead to quite different implications for the role of the economic regulation of airport infrastructure charges.

Then, in Section 3 we will discuss in detail the differences and relative benefits of single-till and dual-till regulation, which are two common forms used for airport regulation. ${ }^{4}$ Roughly, "single till" means that profits derived from airport commercial activities (so-called "concessions") such as the supply of car parking, car rental services, food and beverages, duty-free shopping, etc. are used to cover the fixed cost of the airport's transport-related infrastructure like runways and terminals (so-called "aeronautical services"). The basic idea behind the dual-till approach is to separate out the aeronautical activities from concession activities by ensuring that infrastructure (aeronautical) charges are sufficiently high to fully cover airport infrastructure cost.

The basic insights are summarized at the end of each section and then are further summarized in the conclusions section (Section 4). The discussion partly relies on a recent survey paper by Zhang and Czerny (2012).

\section{Basic Issues in Airport Regulation}

As mentioned above, we discuss four issues in this section, which are of particular importance for the examination of the price regulation of airport monopolies. These are: airport market power, airport market power in combination with potential airline market power (which accounts for the vertical structure of air transport markets), airport congestion, and the supply of airport concession services.

\section{Airport market power}

Airports are regulated economically because they often possess local monopoly market power. More specifically, this means that airport charges for the use of aeronautical infrastructure such as runways and terminals, largely determine the number of passengers in a region. In theory (and sometimes in practice) this doesn't have to be the case. Think of the London area in the UK or the San Francisco Bay area in the US, where citizens can choose among several airports. If an airport increases its infrastructure charges in these areas, some passengers may respond to this by not traveling while some others may make use of rival airports in the same region. The very fact that passengers can choose between different airports in the same region therefore limits the effect of airport infrastructure charges on the overall quantity of travelers in a region. ${ }^{5}$ In Asia and Europe, intermodal competition between air and rail transport can also limit the pricing power of airports because some travelers may

\footnotetext{
${ }^{3}$ As discussed in Basso and Zhang (2007), the "vertical structure" takes the view that as a transportation infrastructure facility, airports reach final consumers (passengers, shippers) both directly - via passenger terminals - and indirectly through air carriers (runways, cargo terminals, and so on). For the latter, an airport is an input provider to the downstream firms (airlines) that compete with each other in the air travel market.

${ }^{4}$ The issue of single-till and dual-till regulation is also relevant for other transport sectors such as the rail industry.

${ }^{5}$ For recent studies on multi-airport competition and its various implications see, among others, Odoni (2009), Mun and Teraji (2012), and Noruzoliaee et al. (2014).
} 
decide to travel by rail if airport infrastructure charges increase. ${ }^{6}$ Transfer passengers who travel from their origin to their destination with one or more stops at hub airports can further limit airport pricing power. Since transfer passengers can typically choose among several hub airports (e.g., from Europe to the United States via hub airports in Paris, London or Frankfurt), this can limit the pricing power of some hub airports. Yet, there are still numerous airports with significant market power. Existing studies show that the demand for aircraft movements at an airport is very inelastic with respect to airport charges: for example, Gillen et al. (1989) calculated the elasticity to be in the range of -0.07 to -0.15 in the context of a North American airport. One reason is that airports in a geographic area may actually serve different routes and hence different markets to some extent. This lack of direct airline service competition curtails the degree of effective competition between airports from the consumer's perspective. (See Bilotkach and Polk (2013) for an interesting recent examination of the issue.) Similarly, Bel and Fageda (2010) found higher aeronautical charges at private unregulated airports in their cross-sectional study of major European airports. Accordingly, as the ownership of airports changes from public to private hands, economic regulation may become increasingly important due to the local monopoly nature of airports.

\section{Airport and airline market power}

For the economic regulation of airports, it is important to recognize the vertical structure of air transport markets. Figure 1 is used to illustrate this issue for the case of a monopoly airport. It shows that the passenger demand depends on the (ticket) price, which is denoted as $p$. As a starting point, we employ the extreme assumption that the number of airlines in competition is so large that ticket prices are determined by the airlines' operating costs per passenger - this is so-called "perfect competition" among airlines - and that these operating costs are solely determined by the airport infrastructure charge. This is a convenient set of assumptions because the ticket price and the airport infrastructure charge are the same in this situation, given by $p$. Airport operating costs are typically very low (especially compared to airport infrastructure costs to be discussed below), and for simplicity we assume that they are equal to zero. ${ }^{7}$ In this situation, the airport profit-maximizing passenger quantity is determined by the intersection between the horizontal axis and the thick dashed line, where the latter displays the gain in airport revenue associated with an increase of the passenger quantity by exactly one. If the revenue gain reached by one additional passenger is positive, then the airport can increase profit by reducing the price. On the other hand, if the revenue gain of an additional passenger is negative, then the airport cannot increase profit by further reducing the price. Only if the revenue gain of an additional passenger is zero, the airport cannot increase profit by a change in the price, implying that the airport's profit is maximized in this situation. The airport's profit-maximizing price is depicted by the thin dashed horizontal line. Importantly, this price is higher than the airport cost of zero in this situation, which leads to a welfare loss equal to the dark-grey area. Thus if there is a monopoly airport and airlines compete heavily, the welfare loss associated with profit-maximizing airport charges can be quite substantial, implying that there may be a need for price regulation.

However, there are a significant number of routes that are served effectively by only a few or even only one airline (e.g., Levine, 1987; Borenstein, 1992; Lazarev, 2013). The welfare loss can be further substantially increased if the resulting airline market power is taken into account. To illustrate this, consider a monopoly airport with the opposite extreme of a monopoly airline operating at the airport (versus numerous airlines in a perfect competitive market considered above). Assume that the airport infrastructure charge is still given by the

\footnotetext{
${ }^{6}$ See Givoni and Dobruszkes (2013) and Jiang and Zhang (2014) and references cited therein.

${ }^{7}$ The insights derived in this part are largely independent of the existence of operating costs, which is why we feel sufficiently comfortable with the assumption of zero airport-operating costs.
} 
thin dashed-horizontal line. In this situation, the airport infrastructure charge and the ticket prices are not the same anymore because like the airport, the airline also charges a markup over its marginal cost. Since the airline's marginal cost is determined by the airport infrastructure charge (in our simplified scenario), the airline chooses the passenger quantity such that the airline revenue gain of an additional passenger is just equal to its marginal cost. This situation thus leads to two markups on marginal cost, one by the airport and the other by the airline, which is why this leads to so-called double marginalization. The welfare loss when there is double marginalization is given by the sum of the dark-grey and the light-grey areas. As can be seen from the figure, the loss is substantially higher than the welfare loss without double marginalization. This illustrates a situation where airports and airlines that have market power can lead to substantial additional welfare losses compared to a situation where only airports possess market power.

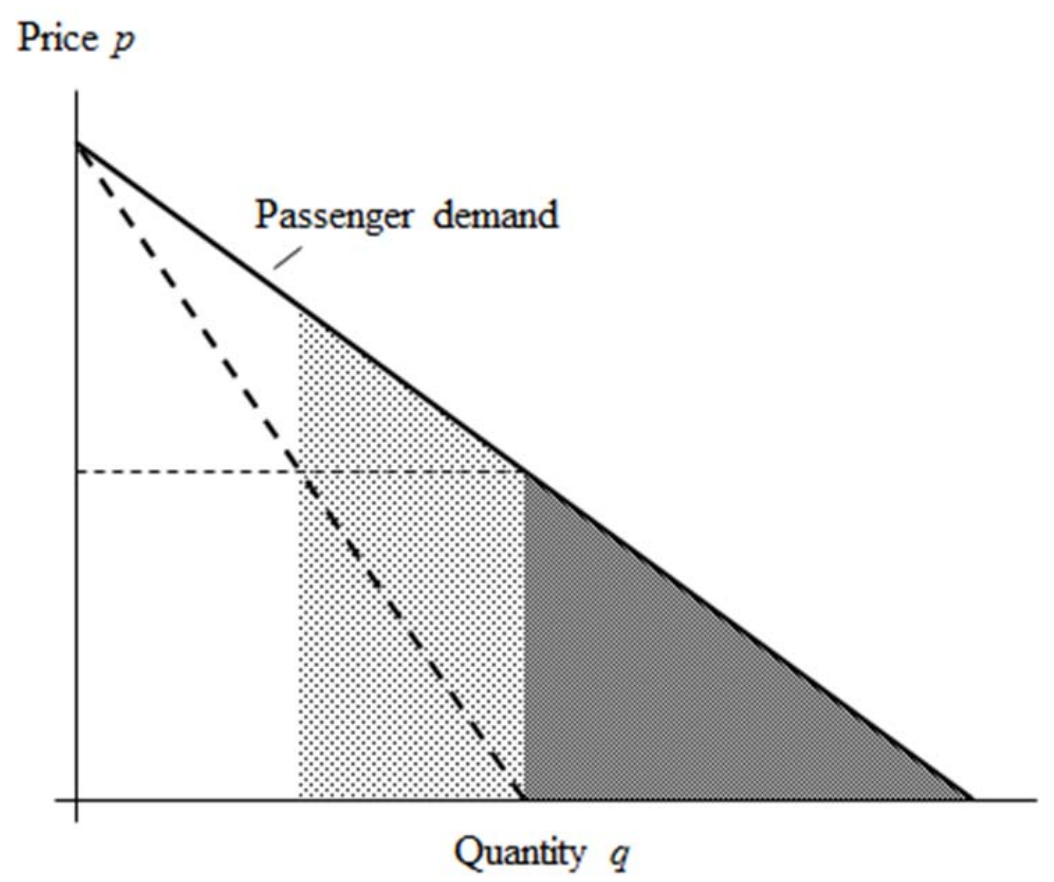

Figure 1. Monopoly airport charges with and without airline market power

The scenario described in Figure 1 can be further used to illustrate the benefits of airport subsidy payments to airlines. Suppose the airport charge is equal to the marginal airport infrastructure costs, which are equal to zero. In this situation the monopoly airline will behave like a monopoly airport with a perfectly competitive airline market and choose a profitmaximizing price, which is determined by the thin dashed-horizontal line while the welfare loss is determined by the dark-grey area. The only way to "convince" the monopoly airline to charge the welfare-maximizing price of zero (recall that airline operating cost were assumed to be zero for simplicity) is to introduce a negative airport infrastructure charge, thus, a perpassenger airline subsidy. The society as a whole can benefit from heavily regulated, very low and even negative airport infrastructure charges when airline market power exists. But, such a system requires subsidy payments also to airports, which have been typically unavailable for the last two decades when airports are under growing pressures to become financially selfsufficient. 


\section{Airport congestion}

Is there any relevant economic force that can work into the opposite direction and lead to a positive airport infrastructure charge from the social viewpoint? This is a relevant question because, if the answer were "yes," then the positive airport charge of a private profitmaximizing operator would be socially optimal, so that price regulation might not be needed. The answer is: yes, the socially optimal airport infrastructure charge may actually be positive if airports are heavily congested and flight delays occur because of shortages in airport capacity.

For the most part of the last decade, air travel delays have been a major problem in many countries. Twenty percent of airline flights in the United States were delayed between 2000 and 2007. ${ }^{8}$ The problem got worse in the first half of 2008, with 29 percent of the flights being delayed or canceled. In fact, the US Department of Transport identified airport congestion reduction as the no. 2 top management challenge, only second to aviation safety (USDOT, 2008). Similar delays have plagued European and Asian airlines and airports. In the case of China - which has become the world's second largest air transport market (behind the United States) since 2005 - more than 30 percent of domestic flights were delayed in recent years.

While the causes of flight delays can vary across countries - for example, weather is a major source of delays in the United States, whereas limited aerospace for civil aviation (versus the military aerospace) is a major source for China - the volume of traffic relative to airport capacity is a major cause. Since airport capacity can often only be expanded in the long term due to the political pressure and environment concerns from residents in the airports' neighborhoods, as well as the length of infrastructure financing and construction, an effective way of dealing with congestion can be to increase the airport infrastructure charge, which reduces the demand for airport infrastructure and thus congestion and delays caused by scarce airport capacity. Another way to deal with shortages in airport capacity, which is widespread in Europe, is the use of airport "slots." With airport slots, airlines need "permission” (i.e., slots) to incorporate slot-constrained airports into their flight schedules, which effectively reduces the demand for airport infrastructure if the number of airport slots is sufficiently small. While both an increase in the infrastructure charge and the use of a limited number of slots can effectively reduce airport traffic and thus congestion, there is an important difference between the two methods. Specifically, an increase in the airport infrastructure charge increases airline costs and thus reduces airline profits, whilst slots can increase airline profits if the slot allocation is based on "grandfather rights." The latter essentially ensures that airlines can use the infrastructure in the future as often as they have in the past, and hence constitutes a valuable access to airport capacity. Since the grandfather rights are usually provided to airlines free of charge (e.g., in Europe), slots can indeed increase airline profits. ${ }^{9}$

\section{Airport concessions}

Since the mid-1980s, airports have been increasingly recognized as full-fledged business enterprises that provide a number of different services to airline industry customers (see, e.g., Doganis, 1992). This development leads to two main facets of an airport's business: the traditional aeronautical operation and the commercial operation ("concessions"). The former refers to the aviation activities associated with runways, aircraft parking, and terminals, whereas the latter includes retailing, advertising, car rentals, car parking, and land rentals.

\footnotetext{
${ }^{8}$ Typically, a flight is considered as delayed when the actual arrival time exceeds the scheduled arrival time by more than 15 minutes.

${ }^{9}$ The positive effect of airport slots on airline profits has also been discussed by, for example, Czerny and Forsyth (2008).
} 
One of the most striking and consistent trends in the airport sector over the last thirty years has been the growing importance of concession revenues (e.g., Zhang and Zhang, 1997, 2003; Forsyth, 2004; Thompson, 2007; Odoni, 2009). Airports worldwide currently derive as much revenue, on average, from concession services as from aeronautical ones (e.g., Zhang and Zhang, 1997; Van Dender, 2007; ACI, 2008; ATRS, 2013). ${ }^{10}$ More importantly, concession operations tend to be more profitable than aeronautical operations (e.g., Jones et al., 1993; Starkie, 2001; Forsyth, 2002).

Starkie (2001) was the first author who came up with the idea that monopoly power of airports might not be an issue from the social viewpoint because airport concessions provide an incentive for airports to reduce aeronautical charges. This described negative effect of concessions on the aeronautical charge is formalized in the models analyzed by Zhang and Zhang (2003) and Oum et al. (2004). Figure 2 illustrates this effect of concession services on the airport charge for aeronautical services (aeronautical charge). This figure is almost identical to Figure 1: It shows the monopoly price in the absence of concession services (the upper horizontal dashed line), which is determined by the intersection of the downward sloping dashed line (increase in revenue per extra passenger) and the horizontal line (operating cost). But, the monopoly airport's rationale behind its aeronautical charge now changes with the presence of concessions. To demonstrate this, suppose that there is a fixed extra profit from concession businesses per-passenger. This is similar to an increase in revenue per extra passenger, meaning that with concession services the dot-dashed (not the dashed line anymore) is relevant for the monopoly airport's charge decision, which leads to a reduction in the monopoly aeronautical charge. Thus, if concession services exist, the airport may reduce aeronautical charges in order to increase the number of passengers and so to stimulate the demand for airport concession services. This is the so-called "complementarity effect” of airport concession services.

However, the above analysis assumes that there is a unidirectional relationship between aeronautical services and concession services. This means that the aeronautical charge can impact both the passenger demand and the concessions demand, while prices for concession services have no effect on the passenger quantity. This may be true because the ticket demand and the demand for concession services are separated in time and, therefore, passengers are not aware of the surplus from concession services when they book a flight (Zhang and Zhang, 2003). On the other hand, the time-separation issue has been somewhat moderated over the last several years with the e-commerce advancement and airports increasingly advertising their concession services on-line (Bracaglia et al., 2014). Furthermore, many passengers, in particular business passengers, are frequent travelers. The assumption that individuals are totally unaware of the surplus associated with concession services can, therefore, be critical for at least this passenger group. For example, business passengers may plan their trip based on the total travel costs including airport car rental charges, and some leisure passengers may well be aware of airport car parking charges when they plan their holiday trip (Czerny, 2013). In fact, empirical studies have found that shopping can depend on traveling activities to some extent. ${ }^{11}$ For instance, Geuens et al. (2004) reported based on a sample of passengers at Belgian airports, that airports can elicit special shopping behavior, which may imply that the aggregate shopping activities (sum of shopping activities inside and outside the airport area) do depend on traveling activities. Furthermore, Van Dender (2007) found empirically that the

\footnotetext{
${ }^{10}$ For instance, Zhang and Zhang (1997) reported that Hong Kong International Airport generated an equal amount of revenue from its aeronautical and commercial operations in 1979, while in the late 1980s and 1990s its concession revenue accounted for $66-70 \%$ of total revenue. Van Dender's (2007) investigation of fifty-five large US airports found that concession revenue represents more than half of the total airport revenue during the 1998-2002 period (see Doganis, 1992 for figures on earlier years in the United States).

${ }^{11}$ For a useful literature review, see D'Alfonso et al. (2013).
} 
per-passenger concession revenues are declining in passenger quantity. This finding is consistent with the concept that concession prices can change the passenger demand, since a reduction of the concession prices may increase the passenger quantity and thereby reduce the per-passenger concession revenue.

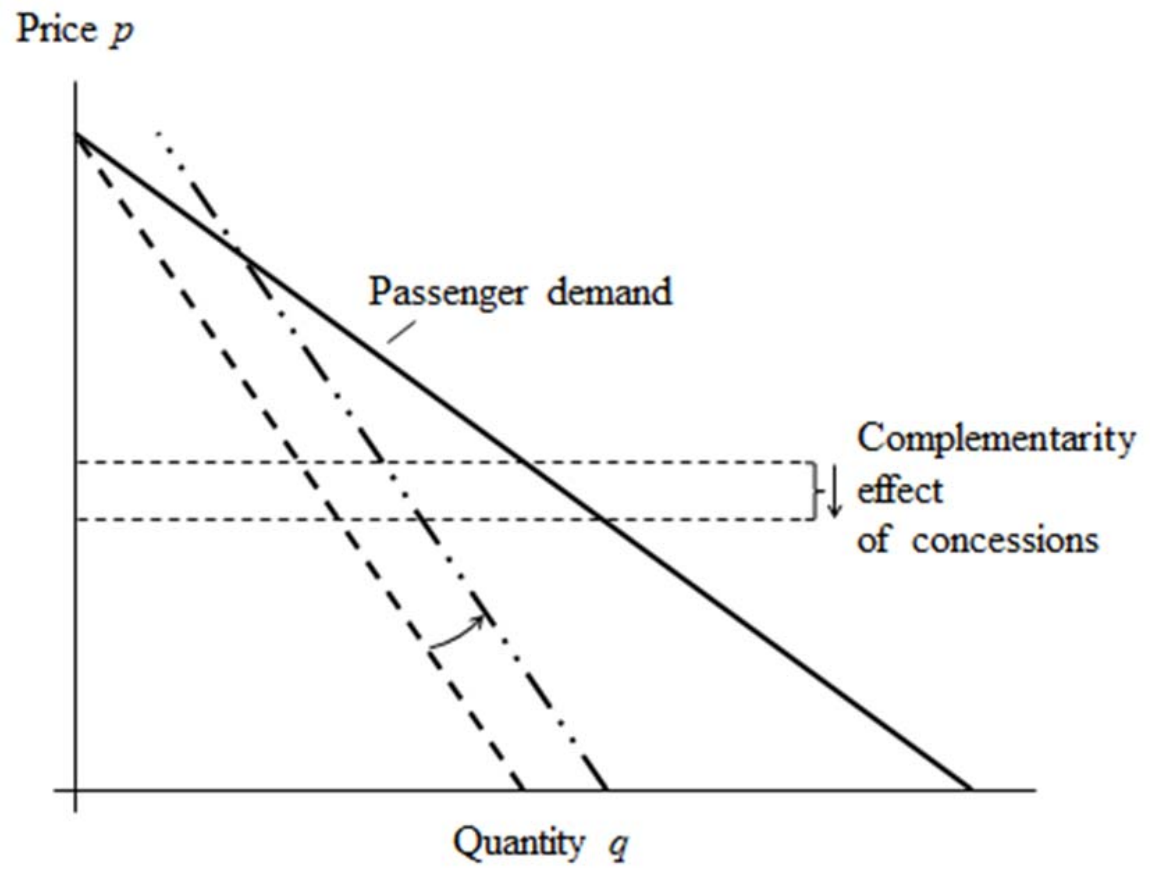

Figure 2. The complementarity effect of concessions on aeronautical charges

To see how the effect of concession services on passenger demand can change the monopoly aeronautical charge, note that the supply of concession services can increase the benefits of traveling and shift passenger demand - this is the so-called "demand effect" of airport concession services. As a result, it can be that the private aeronautical charge is actually increased with the existence of concession services. Czerny (2006) uses a linear model to numerically show that concession services lift the passenger demand and that the aeronautical charge can be increased with the existence of concession revenues relative to the situation without concessions.

Another issue regarding Starkie's argument relates to the question of whether monopoly power of airports should be of policy concern in the presence of airport concessions. Zhang and Zhang (2003) show that in the presence of concessions, the pricing policy of a private, unregulated airport would not attain socially optimal levels; in effect, such an airport would charge a higher price than the socially optimal level. Essentially, while airport concessions may provide an incentive for a private, unregulated airport to reduce its aeronautical charge, concessions will play the same role in the reduction of aeronautical charge for a public airport that maximizes welfare.

\section{Lessons learned}

- Economic regulation of airports may be necessary, owing to airports generally exhibiting properties of local monopolies. The need for regulation is in general independent of whether airports have significant concession revenues or not. 
- Welfare maximization requires subsidy payments to airlines and airports if airports are uncongested, while this may not be the case for congested airports.

- Airlines can benefit from the use of slots when airports are congested.

- The (net) effect of concessions on the profit-maximizing aeronautical charge can be negative or positive depending on whether the complementarity effect or, respectively, the demand effect dominates.

\section{Single-till versus Dual-till}

The previous section mentioned that the welfare optimal-aeronautical airport charge is zero or even negative when airlines have market power. On the other hand, it is unclear whether the supply of concession services will exert downward pressure on the monopoly aeronautical charge or increase the unregulated monopoly aeronautical charge. The fact that most airports around the world operate under public ownership, or under private ownership but are economically regulated, might indicate that the effect of airport concessions on the incentives to reduce aeronautical charges is limited.

With the background laid out in Section 2, this section discusses the single-till and dual-till approaches to the regulation of aeronautical charges. A formal definition of the single-till and dual-till approaches is provided first, which is then followed by an examination of the policy implications.

\section{Single-till and dual-till: What does it mean?}

The analysis of single-till and dual-till airport regulation centers around the question whether profits from the supply of airport concession services, denoted as $S$, should be used to cover the airport infrastructure cost, denoted as $F$. The most direct way of regulating airport aeronautical charges (as opposed to the regulation of revenues, profits, or the rate of return on assets) on which this chapter concentrates, is to choose an upper limit for the airport aeronautical charge (the "price cap"). We denote this upper limit by $\tau .^{12}$

With single-till regulation (indicated by superscript ST), the profits derived from airport concession services are used to cover the airport infrastructure cost. If the airport is supposed to fully cover infrastructure cost through own revenues (i.e., there are no subsidy payments from the government to the airport), the price cap is derived from the formula:

$$
\tau^{S T}=\min \left\{\tau: \tau=\frac{F-S}{q(\tau)}\right\} .
$$

The right-hand side involves the difference between infrastructure costs and commercial profits divided by the passenger quantity. A price cap equal to this average value ensures strict airport cost recovery. This shows that a positive aeronautical charge is required to cover infrastructure cost if concession profits are less than infrastructure cost, while the aeronautical charge may become negative if concession revenues are sufficiently high. Note that the single-till formula recognizes that the passenger quantity is a function of the aeronautical charge, i.e. $q=q(\tau)$. The "min" operator is used because the same revenue can typically be achieved with either a high aeronautical charge or a low aeronautical charge when the demand is strictly downward-sloping, and because welfare is higher when the lower aeronautical

\footnotetext{
12 The single-till and dual-till distinction can also carry over to cost-based regulation where the rate-of-return (ROR) can be set on the capital investment for both the aeronautical and non-aeronautical operations (single-till), or strictly on the aeronautical operations (dual-till). For a comparison between price-cap regulation and ROR regulation in terms of their impact on airport capacity and service quality, see Yang and Zhang (2012).
} 
charge is chosen. Figure 3 illustrates this point. The figure shows that the same revenues can be achieved with a high or a low airport aeronautical charge (for simplicity, the illustration assumes, again, that the aeronautical charge and the ticket price are the same, i.e. $p=\tau$, which means that airline market is perfectly competitive). Given that the shaded areas are equal to $F-S$, the single-till price cap is determined by the lower of the two aeronautical charges indicated by $\tau^{S T}$.

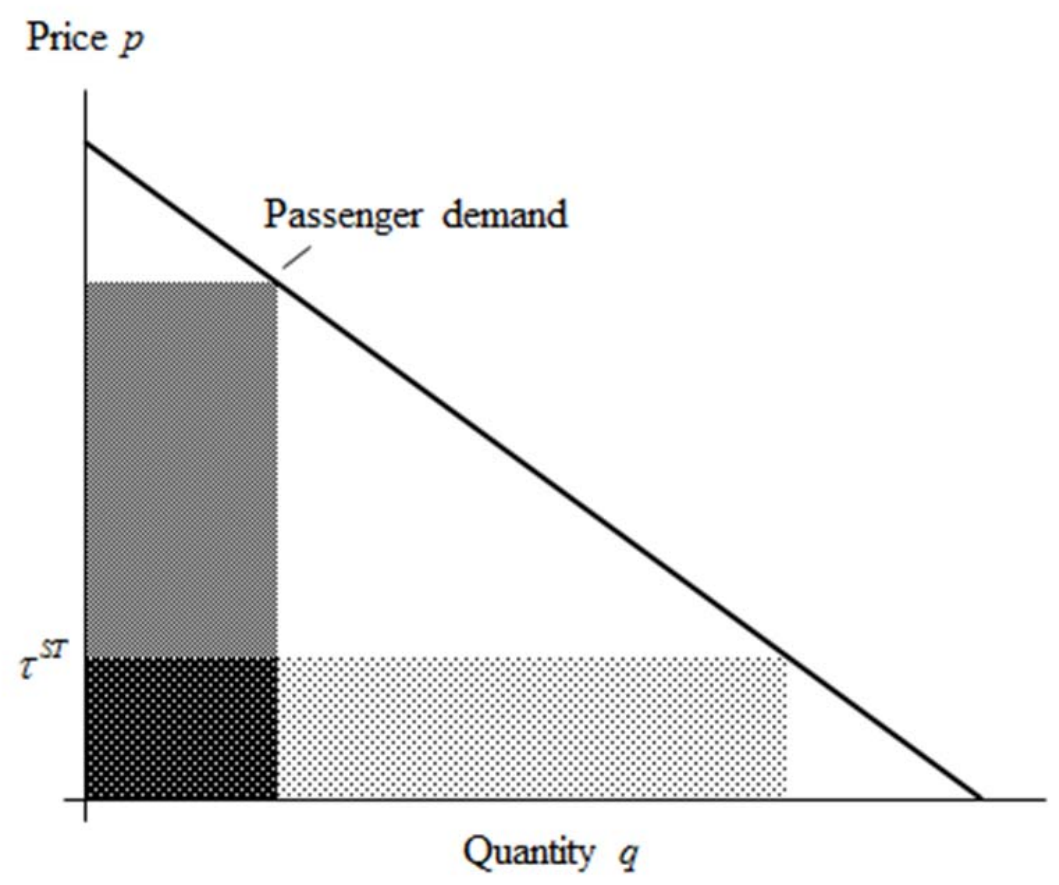

Figure 3. Single-till regulation

With dual-till regulation (indicated by superscript $D T$ ), aeronautical charges are supposed to cover the entire infrastructure costs (i.e., profits from concession services are not used to cover infrastructure cost at all). In this case, the price-cap formula can be written as

$$
\tau^{D T}=\min \left\{\tau: \tau=\frac{F}{q(\tau)}\right\} .
$$

This shows that the price-cap is chosen to ensure infrastructure cost recovery from aeronautical airport charges, which typically requires a high price cap under the dual-till relative to the single-till approach. ${ }^{13}$

Dual-till represents a relatively recent regulatory innovation, while single-till regulation represents the more traditional approach (Bilotkach et al., 2012). One difficulty with the implementation of dual-till regulation, which has already been pointed out by Beesley (1999), is that the fixed airport costs must be divided into the infrastructure costs and the costs related only to concession businesses. While this adds some arbitrary element to the comparison of single-till regulation and dual-till regulation, for our analysis it is sufficient that the stakeholders somehow agree upon one specific division of the fixed infrastructure costs that

\footnotetext{
${ }^{13}$ Empirical work by Bilotkach et al. (2012) supports this analytical prediction.
} 
leads to a positive value of $F$. (Note that the two approaches are the same if all fixed airport costs are attributed to concession services.)

\section{Policy implications}

Recall that welfare-optimal (i.e., "first best”) airport charges may imply substantial amounts of subsidy payments from the airport to the airlines. Given that airport revenues are supposed to ensure airport cost recovery, the issue here is to find a way to maximize welfare subject to airport cost recovery ("second best"). Ramsey (1927) has shown that the second-best prices are inversely related to the price elasticities of demands, which means that markups should be higher in the markets where customers are less price sensitive. For airports, Czerny (2006) shows that the single-till approach may better approximate Ramsey-optimal aeronautical charges and prices for concession goods. This is because, as indicated above, the single-till price cap is typically lower than the dual-till price cap, which means that the single-till approach may better approximate the welfare-optimal airport charges, thereby limiting the issues of airport market power and double marginalization. Czerny (2006) demonstrates the result for an airport that is non-congested and that has a perfectly competitive airline market. Yang and Zhang (2011) show that Czerny's result continues to hold when airlines have market power. ${ }^{14}$

What if the airport is congested? The discussion in the previous section, however, showed that the welfare-optimal aeronautical charges may be positive for congested airports. Consequently, a major critique of the single-till approach is that aeronautical charges are actually set too low at congested airports. More specifically, when the single-till approach is applied to a capacity-constrained airport, aeronautical charges must be lowered - as more profits are made from commercial activities - so that the airport may become heavily congested as a result. The charge under single-till regulation may, therefore, be too low as compared to the efficient charge, while the dual-till charge is higher than the single-till charge and may be closer to the efficient charge (for example, Beesley, 1999; Starkie 2001).

This intuition is formalized by Yang and Zhang (2011) in their analysis of single-till and dualtill price-cap regulations for a congested airport (where airlines may or may have market power). While confirming Czerny's result for an uncongested airport - that is, single-till price-cap regulation dominates price-cap regulation in terms of social welfare when airport congestion is not a major problem - they further show that dual-till price-cap regulation can be more desirable than single-till price-cap regulation at a congested airport. Essentially, when an airport is congested, the efficient airport charge should increase in users' value of time. With positive time value, users' time cost arising from delays is part of social welfare. More specifically, they show that when an airport is not able to cover its fixed costs with an efficient aeronautical charge and its concession profit, then the single-till approach dominates the dual-till approach. On the other hand, when the efficient aeronautical charge covers the airport cost associated with aeronautical services and airport congestion is significant, then dual-till regulation performs better. For the intermediate cases, the comparison depends on whether the efficient aeronautical charge is greater than the average of the aeronautical charges under single-till and dual-till regulation. If so, then dual-till regulation dominates single-till regulation; otherwise, single-till regulation is more efficient.

\footnotetext{
${ }^{14}$ A related earlier study is Zhang and Zhang (1997). Like Czerny (2006), they considered an airport that is noncongested and that has a perfectly competitive airline market. Zhang and Zhang (1997) examined the optimal pricing in a model where the airport's aeronautical and concession services are considered together with an overall break-even constraint. They found that the social optimum may require a subsidy from concessions to aeronautical operations, implying the optimality of single-till regulation.
} 
To focus on the comparison between the single-till and dual-till schemes, Yang and Zhang (2011) do not consider the role of slots in their paper. As indicated above, a major problem with the single-till approach is that aeronautical charges are set too low at congested airports when economic efficiency requires them to be raised. This problem can be alleviated, at least partly, by the control and management of airport slots, including slot auctions and slot trading. In Europe, in particular, the single-till price-cap regulation normally comes along with slots. And, airports slots are highly valuable assets for many airlines under these conditions. ${ }^{15}$ This is because single-till reduces the airline payments to the airport (thus, airline operating costs), while imposing restrictions on the airline supply and thus competition, which altogether tends to increase market prices and airline profits.

\section{Lessons learned}

- Single-till regulation can control airport market power and limit the detrimental welfare effects of airport market power, airline market power, and double marginalization.

- Dual-till regulation can be used to control excessive congestion.

- Single-till can have positive distributional effects for airlines when airports are congested and slot constrained.

\section{Concluding Remarks}

This book chapter has discussed the relative benefits of single-till and dual-till regulatory regimes. To do this, it started with a discussion of several important features of airport markets, including airport and airline market power, double marginalization, scarce airport infrastructure and congestion, as well as the growing importance of airport concession services. The discussion derived several insights, which are relevant for the choice between single-till and dual-till regulatory regimes. Specifically, it turned out that airport deficits are likely to occur if airport charges are chosen to maximize welfare and airport infrastructure capacity is not scarce. With scarce airport infrastructure capacity, the picture changes because an increase in the aeronautical charge can then be used to reduce airport demand and thus congestion and delays, which tends to enhance welfare. Alternatively, airport slots may be used to control congestion, which can have a positive distributional effect for airlines.

Of major importance for the choice between single-till and dual-till regulatory regimes is, however, the growing importance of airport concession services. Some authors actually go so far and claim that the very existence of airport concessions may eliminate the need for the economic regulation of airport infrastructure charges. Nevertheless, further analysis suggests that the pricing policy of a private, unregulated airport would not attain the social optimum in the presence of concessions. Even on the second-best ground, the theoretical evidence is ambiguous because there exist both the complementarity and demand effects of airport concession services, which work into opposite directions. The complementarity effect captures that airports can benefit from a reduction in the aeronautical charge because this increases the passenger quantity and thus the demand for concession services. The demand effect captures that the supply of airport concession services can increase passenger demand and the profit-maximizing monopoly aeronautical charge. Thus the net effect of concession services on the monopoly aeronautical charge depends on the relative strength of these two opposing effects and is, in general, ambiguous.

Based on these insights, the relative benefits of single-till and dual-till regulatory regimes have been compared. The basic difference between these two approaches is that single-till allows full control over airport profits because the profits derived from concession services

\footnotetext{
${ }^{15}$ Brueckner (2009) shows that slot auctions or slot trading can lead to an efficient outcome.
} 
are used to finance airport infrastructure. Under dual-till regulation, aeronautical and concession businesses are separated in the sense that profits derived from concession businesses are not used to finance airport infrastructure. Since the single-till approach will typically lead to lower aeronautical charges, this approach can be used to better control airport market power and problems of double marginalization. On the other hand, the dual-till approach may be more appropriate for heavily congested airports. However, a combination of single-till regulation and slot constraints may also effectively control congestion, and would be beneficial for airlines relative to dual-till regulation.

The discussions in this chapter have also raised issues for further research. First, our discussion suggests the importance of a better understanding of aeronautical service/concessions interaction on the demand side. Alternative modeling specifications have been proposed and analyzed by researchers, and more complete and rigorous treatments of the issue start to emerge in the literature (e.g., Czerny and Lindsey, 2014; Flores-Fillol et al., 2014). Second, in addition to pricing, another major activity for airports is capacity investment (e.g., Forsyth, 2007; Zhang and Zhang, 2010). It is important to discuss the relative benefits of single-till and dual-till regulatory regimes by endogenizing airport capacity choice as well. Finally, there is a need for empirical work testing, for example, alternative analytical specifications of the interaction between aeronautical and concession services. 


\section{References}

ACI (2008), ACI Airport Economics Survey 2008, Montreal, QC: Airports Council International (ACI).

ATRS (2013). The ATRS (Air Transport Research Society) Airport Performance Benchmarking Report: Global Standards for Airport Excellence, 3-volume report, published by the Centre for Transportation Studies, Sauder School of Business, University of British Columbia, Vancouver, BC.

Basso, L. and Zhang, A. (2007). An interpretative survey of analytical models of airport pricing. In: Darin Lee (ed.), Advances in Airline Economics, Volume 2, Elsevier, pp. 89-124.

Beesley, M.E. (1999). Airport regulation. In: M.E. Beesley (ed.), Regulating Utilities: A New Era? London: Institute of Economic Affairs.

Bel, G. and Fageda, X. (2010). Factors explaining charges in European airports: Competition, market size, private ownership and regulation. Journal of Regulatory Economics, 37, 142161.

Bilotkach, V., Clougherty, J.A., Mueller, J. and Zhang, A. (2012). Regulation, privatization, and aeronautical charges: Panel data evidence from European airports. Journal of Regulatory Economics, 42, 73-94.

Bilotkach, V. and Polk, A. (2013). The assessment of market power of hub airports. Transport Policy, 29, 29-37.

Borenstein, S. (1992). The evolution of U.S. airline competition. Journal of Economic Perspectives, 6, 45-73.

Bracaglia, V., D’Alfonso, T. and Nastasi, A. (2014). Competition between multiproduct airports. Unpublished manuscript, University of Rome "La Sapienza”.

Brueckner, J.K. (2009). Price vs. quantity-based approaches to airport congestion management. Journal of Public Economics, 93, 681-690.

Czerny, A.I. (2006). Price-cap regulation of airports: Single-till versus dual-till. Journal of Regulatory Economics, 30, 85-97.

Czerny, A.I. (2013). Public versus private airport behavior when concession revenues exist. Economics of Transportation, 2, 38-46.

Czerny, A.I. and Forsyth, P. (2008). Airport regulation, lumpy investments and slot limits. Unpbublished manuscript, VU University of Amsterdam.

Czerny, A.I. and Lindsey, R. (2014). Multiproduct pricing with core goods and side goods. Unpublished manuscript, VU University Amsterdam.

D'Alfonso, T., Jiang, C. and Wan, Y. (2013). Airport pricing, concession revenues and passenger types. Journal of Transport Economics and Policy, 47, 71-89.

Doganis, R. (1992). The Airport Business, London: Routledge.

Flores-Fillol, R., Iozzi, A. and Valletti, T. (2014). Platform pricing and consumer foresight: The case of airports. Unpublished manuscript, Universitat Rovira i Virgili.

Forsyth, P. (2002). Regulation under stress: Developments in Australian airport policy, Paper presented at the "Hamburg Aviation Workshop on the State of Airport Policy - Australia, North America and Europe,” Hamburg, Germany. 
Forsyth, P. (2004). Locational and monopoly rents at airports: Creating them and shifting them. Journal of Air Transport Management, 10, 51-60.

Forsyth, P. (2007). The impacts of emerging aviation trends on airport infrastructure. Journal of Air Transport Management, 13, 45-52.

Gillen, D.W., Oum, T.H. and Tretheway, M.W. (1989). Airport pricing principles: An application to Canadian airports. Journal of Transportation Research Forum, 29, 28-34.

Geuens, M., Vantomme, D. and Brengman, M. (2004). Developing a typology of airport shoppers. Tourism Management, 25, 615-622.

Givoni, M. and Dobruszkes, F. (2013). A review of ex-post evidence for mode substitution and induced demand following the introduction of high-speed rail. Transport Reviews, 33, 720-742.

Jiang, C. and Zhang, A. (2014). Effects of high-speed rail and airline cooperation under hub airport capacity constraint. Transportation Research Part B, 60, 33-49.

Jones, I., Viehoff, I. and Marks, P. (1993). The economics of airport slots. Fiscal Studies, 14, 37-57.

Lazarev, J. (2013). The welfare effects of intertemporal price discrimination: An empirical analysis of airline pricing in U.S. monopoly markets, mimeo, Graduate School of Business, Stanford University.

Levine, M.E. (1987). Airline competition in deregulated markets: Theory, firm strategies and public policy. Yale Journal on Regulation, 4, 283-344.

Lin, M.H. (2013). Airport privatization in congested hub-spoke networks. Transportation Research Part B, 54, 51-67.

Matsumura, T. and Matsushima, N. (2012). Airport privatization and international competition. Japanese Economic Review, 63, 431-450.

Mun, S. and Teraji, Y. (2012). The organization of multiple airports in a metropolitan area. Journal of Transport Economics and Policy, 46, 221-237.

Noruzoliaee, M., Zou, B. and Zhang, A. (2014). Airport Partial and Full Privatization in a Multi-airport Region: Focus on Pricing and Capacity. Working paper, University of Illinois at Chicago.

Odoni, A. (2009). Chapter 12: Airports. In: P. Belobaba, W. Swelbar and C. Barnhart (Eds.), The Global Airline Industry, New York: Wiley, pp. 343-376.

Oum, T.H., Zhang, A. and Zhang, Y. (2004). Alternative forms of economic regulation and their efficiency implications for airports. Journal of Transport Economics and Policy, 28, 217-246.

Ramsey, F.P. (1927). A contribution to the theory of taxation. Economic Journal, 37, 47-61.

Starkie, D. (2001). Reforming UK airport regulation. Journal of Transport Economics and Policy, 35, 119-135.

Thompson, B. (2007). Airport retailing in the UK. Journal of Retail and Leisure Property, 6, 203-211.

USDOT (2008). Top Management Challenges, Report Number: PT-2009-005, Issued on November 17, 2008, US Department of Transportation, Washington DC.

Van Dender, K. (2007). Determinants of fares and operating revenues at US airports. Journal of Urban Economics, 62, 317-336. 
Winston, C. and de Rus, G. (2008). Aviation Infrastructure Performance: A Study in Comparative Political Economy, Washington DC: Brookings Institution Press.

Yang, H. and Zhang, A. (2011). Price cap regulation at congested airports. Journal of Regulatory Economics, 39, 293-312.

Yang, H. and Zhang, A. (2012), "Impact of regulation on transport infrastructure capacity and service quality,” Journal of Transport Economics and Policy, 46, 415-430.

Zhang, A. and Czerny, A.I. (2012). Airports and airlines economics and policy: An interpretive review of recent research. Economics of Transportation, 1, 15-34.

Zhang, A. and Zhang, Y. (1997). Concession revenue and optimal airport pricing. Transportation Research Part E, 33, 287-296.

Zhang, A. and Zhang, Y. (2003). Airport charges and capacity expansion: Effects of concessions and privatization. Journal of Urban Economics, 53, 53-75.

Zhang, A. and Zhang, Y. (2010). Airport capacity and congestion pricing with both aeronautical and commercial operations. Transportation Research Part B, 44, 404-413. 